\title{
Distribución geográfica y caracterización fenotípica y molecular de Neonectria fuckeliana, asociado a cancros fustales de Pinus radiata en Chile
}

\author{
Geographical distribution and phenotypic and molecular characterization of Neonectria fuckeliana, \\ associated with upper-stem cankers of Pinus radiate in Chile
}

\author{
Cristian González ${ }^{\text {abb*, }}$, Rodrigo Morales b ${ }^{\text {b }}$, Ricardo Riegel c, Marcos Aravena ${ }^{\text {b }}$, Eduardo Valenzuela ${ }^{\text {d }}$ \\ *Autor de correspondencia: a Universidad Austral de Chile, Facultad de Ciencias Forestales y Recursos Naturales, \\ Escuela de Graduados, Valdivia, Chile, tel.: 56-63-2221491, cd.gonzalez.sanchez@gmail.com \\ ${ }^{\mathrm{b}}$ Universidad Austral de Chile, Facultad de Ciencias Forestales y Recursos Naturales, \\ Instituto de Conservación Biodiversidad y Territorio, Laboratorio de Salud de Bosques y Ecosistemas, Valdivia, Chile. \\ c Universidad Austral de Chile, Facultad de Ciencias Agrarias, Instituto de Producción y Sanidad Vegetal, Valdivia, Chile. \\ ${ }^{\text {d} U n i v e r s i d a d ~ A u s t r a l ~ d e ~ C h i l e, ~ F a c u l t a d ~ d e ~ C i e n c i a s, ~ I n s t i t u t o ~ d e ~ B i o q u i ́ m i c a ~ y ~ M i c r o b i o l o g i ́ a, ~ V a l d i v i a, ~ C h i l e . ~}$
}

\begin{abstract}
SUMMARY
Neonectria fuckeliana is a fungus that lives in the northern hemisphere as a saprophyte or weakly pathogenic on native conifers. However, in New Zealand and Chile it is a pathogen in commercial plantations of Pinus radiata causing upper-stem cankers and malformations. The aims of this study were to determine the geographical distribution of N.fuckeliana in Chile and to characterize, phenotypically and molecularly, $N$. fuckeliana isolated from four geographical locations (Carahue, Toltén, Pucón and Paillaco). The geographical distribution was determined through field surveys, based on the symptoms and signs associated with the presence of the pathogen. Phenotypic characterization included the color of colonies, growth rates and size of conidia. Molecularly, the internal transcribed spacer (ITS) region of the rDNA was amplified using primers ITS5, ITS4 and NS1, NS2 and sequenced. According to the results, $N$. fuckeliana is distributed along $>450 \mathrm{~km}$ in the coast from Biobío Region (5860100N - 627358E 18H) to Los Lagos Region $(5423863 \mathrm{~N}-636153 \mathrm{E} 18 \mathrm{G})$ in Chile. Phenotypically, three colors of colonies were identified: red, yellow and pale yellow; red being the predominant $(>70 \%$ ) in all locations. In addition, it was determined that isolates recovered in Region of La Araucanía had higher growth and conidia sizes than those of Los Ríos Region. Molecular characterization confirmed the identification of $N$. fuckeliana, with $99 \%$ identity with sequences of $N$. fuckeliana from Europe and New Zealand deposited in Genbank (KJ022020 and HQ840404) without genetic differences among Chilean isolates obtained in this study.
\end{abstract}

Key words: Neonectria fuckeliana, cankers, 18S rRNA internal transcribed spacer ITS.

\section{RESUMEN}

Neonectria fuckeliana es un hongo saprófito o débilmente patógeno sobre coníferas nativas del hemisferio Norte. Sin embargo, en Chile y Nueva Zelanda se presenta como patógeno sobre plantaciones de Pinus radiata, causando cancros y malformaciones fustales. El objetivo de este estudio fue determinar la distribución geográfica de esta enfermedad en Chile y caracterizar fenotípica y molecularmente aislados de N. fuckeliana provenientes de cuatro localidades (Carahue, Toltén, Pucón y Paillaco). La distribución se determinó con prospecciones en terreno, atendiendo a síntomas y signos asociados a la presencia del patógeno. La caracterización fenotípica evaluó el color de las colonias, tasas de crecimiento y tamaño de conidias. Molecularmente se amplificó y secuenció la región parcial del gen $18 \mathrm{~S}$ rRNA y del espaciador interno transcrito ITS. Según los resultados, este patógeno se encuentra distribuido a lo largo $(>450 \mathrm{~km})$ de la zona costera de Chile, desde la región del Biobío (5860100N - 627358E 18H) hasta la de Los Lagos (5423863N - 636153E 18G). Fenotípicamente se identificaron tres colores de colonias: rojas, amarillas y amarillo pálidas, siendo predominante el color rojo (> 70 \%) en todas las localidades. Los aislados recuperados desde localidades de La Araucanía presentaron mayores crecimientos y tamaños de conidias que las de Los Ríos. La caracterización molecular corroboró la identificación de N. fuckeliana, con un $99 \%$ de identidad con secuencias de N. fuckeliana de Europa y Nueva Zelanda depositadas en Genbank (KJ022020 y HQ840404) y sin demostrar diferencias genéticas entre los aislados chilenos obtenidos en este estudio.

Palabras clave: Neonectria fuckeliana, cancros, 18S rRNA, espaciador interno transcrito ITS. 


\section{INTRODUCCIÓN}

Neonectria fuckeliana (C. Booth) Castl. et Rossman (sin. Nectria fuckeliana C. Booth) es un hongo Ascomycota, originario del hemisferio norte donde ataca diversas especies coníferas de los géneros Abies, Larix, Picea y Pinus. Penetra por heridas y actúa como saprófito o débilmente patógeno (Roll-Hansen y Roll-Hansen 1979, Vasiliauskas y Stenlid 1998).

En el hemisferio Sur los países afectados por este agente son Chile y Nueva Zelanda, donde el hongo genera cancros y malformaciones fustales que comienzan en las heridas de poda en plantaciones de Pinus radiata D. Don, lo que produce pérdida de calidad en los productos podados de la primera y segunda troza. En Nueva Zelanda, la enfermedad se detectó a mediados de los años ' 90 en árboles podados y en la actualidad se distribuye en la zona costera de la isla Sur (Dick y Crane 2009). En Chile, el primer reporte se efectuó en 2008 en la comuna de Toltén, Región de La Araucanía, donde se observaron malformaciones y cancros en los fustes de plantaciones de 7 y 15 años (Morales 2009).

Neonectria fuckeliana es un hongo pleomórfico que presenta dos formas asexuales (anamorfos), las que corresponden a Cylindrocarpon cylindroides var. tenue y Acremonium-like. El primero no se ha presentado en aislamientos de laboratorio, siendo el segundo estado el más común de encontrar en medios de cultivos artificiales (Brayford et al. 2004, Castlebury et al. 2006, Crane et al. 2009).

La fase sexual de $N$. fuckeliana forma peritecios esféricos (diámetro de 300 a $400 \mu \mathrm{m}$ ) de color rojos a rojo marrón. Estos cuerpos fructíferos crecen en forma grupal sobre la corteza de los árboles afectados (Brayford et al. 2004). Los ascos son cilíndricos clavados, uni-tunicados, con un anillo de refracción en el ápice y, comúnmente contienen ocho ascosporas elipsoidales hialinas con un septo en el centro y dimensiones entre 12,5 - 15,5 x 4,7-6,0 $\mu \mathrm{m}$ (Brayford et al. 2004). El estado asexual Acremonium-like, se presenta en aislamientos obtenidos desde peritecios y macroconidios de C. cylindroides, generando abundante presencia de fiálides $(30-70 \times 1,5-3,5 \mu \mathrm{m})$ y conidias de $4-10 \times 2,2-3,3 \mu \mathrm{m}$, las cuales son unicelulares, hialinas, cilíndricas a elipsoidales o periformes en algunos casos (Brayford et al. 2004, Osorio et al. 2014).

Desde la detección del hongo en plantaciones de $P$. radiata, se atribuyó que la penetración es a través de heridas de podas, debido a que los cancros comienzan en ese punto. Sin embargo, nuevas investigaciones han detectado la presencia de N. fuckeliana en árboles sin podar, por lo cual se presume que puede penetrar por vías alternativas o bien ocurre en forma críptica o como endófito (Ramsfield et al. 2013). Por otra parte, aún se desconoce el rol de C. cylindroides en la dispersión de la enfermedad y la importancia que pudiera tener en la infección. Cylindrocarpon cylindroides es poco frecuente en la naturaleza y tampoco ocurre en cultivos artificiales, lo que ha impedido conducir estudios con este estado asexual de $N$. fuckeliana (Hopkins et al. 2012).

En Chile, los primeros antecedentes biológicos, fueron desarrollados por Molina et al. (2012), con la caracterización morfológica de los cultivos de Acremonium-like. Por otra parte, Morales et al. (2013) detectó C. cylindroides en campo y Osorio et al. (2014) demostró la relación de $N$. fuckeliana y C. cylindroides in vitro por medio de métodos microbiológicos y moleculares. La investigación en Chile se ha centrado en conocer los aspectos biólogos del patógeno y para complementar las líneas de investigación, el presente trabajo tiene por objetivo determinar la distribución geográfica de este patógeno y caracterizar de forma fenotípica y molecular aislados de $N$. fuckeliana provenientes de distintas localidades de Chile.

\section{MÉTODOS}

Distribución geográfica. La prospección de la distribución de la enfermedad en Chile se efectuó entre los años 2011 y 2013, mediante visitas a terreno realizadas en plantaciones de $P$. radiata entre las regiones de Valparaíso y de Los Lagos. En cada localidad se buscaron síntomas y signos asociados a la enfermedad y al mismo tiempo se colectaron muestras de estructuras fúngicas sospechosas, como peritecios o esporodoquios, las que se transportaron al laboratorio para su posterior análisis.

Material biológico y cultivos monospóricos. Desde 40 árboles individuales, distribuidos en cuatro localidades de las regiones de La Araucanía y Los Ríos (cuadro 1), se colectaron 40 muestras. Estas consistieron en trozos de corteza de $5 \times 5 \mathrm{~cm}$ con presencia de grupos de peritecios maduros.

Los cultivos monospóricos se realizaron a partir de ascosporas, recuperadas desde los grupos de peritecios colectados. Con este propósito, previo a inducir la esporulación, cada muestra se desinfectó en forma superficial en etanol al $70 \%$ por cuatro minutos, luego con hipoclorito de sodio al 2,5\% por dos minutos y, por último, un lavado en agua destilada estéril por dos minutos. La esporulación se recogió en tubos de ensayo estériles con $5 \mathrm{~mL}$ de agua destilada estéril. Se tomó una alícuota $(0,3 \mathrm{~mL})$ de esta última suspensión de esporas y se sembró en triplicado en agar agua al $3 \%$, suplementado con $0,05 \mathrm{mg} \mathrm{mL}^{-1} \mathrm{de}$ estreptomicina, para luego incubar a $23{ }^{\circ} \mathrm{C}$ por 24 a 48 horas. Bajo lupa estereoscópica y microscopio se aislaron ascosporas germinadas, las cuales se transfirieron individualmente a una nueva placa con agar malta (AM) al $2 \%$ y se incubaron a $23^{\circ} \mathrm{C}$ por 20 días.

Finalmente, se obtuvieron tres aislados monospóricos por cada muestra, lo que generó un total de 120 aislados (30 por localidad), seleccionándose de forma aleatoria 40 aislados (10 por localidad). Paralelamente se almacenó cada aislado de forma triplicada en tubos de ensayo con AM al $2 \%$ a $4{ }^{\circ} \mathrm{C}$. 
Caracterización fenotípica. Se procedió a realizar una caracterización fenotípica de los 10 aislados seleccionados por localidad (cuadro 1). Esta consistió en la medición de las variables de color de colonias, tasas de crecimiento y tamaño de las conidias.

La medición del color se realizó luego de haber mantenido en incubación los aislados por 20 días en AM al $2 \%$. La coloración se determinó por el reverso de la placa utilizando una tabla de color de suelos Munsell (Munsell 1971).

Las tasas de crecimiento se determinaron luego de sembrar discos de agar con micelio de $5 \mathrm{~mm}$ de diámetro en el centro de una placa con AM al $2 \%$ mantenidos en incubación a $23{ }^{\circ} \mathrm{C}$ en oscuridad. Se realizaron tres repeticiones por aislado. El diámetro de colonia se determinó con una lupa estereoscópica por el reverso de la placa. Cada dos días se tomaron medidas en dos ejes perpendiculares entre sí. Con esta información se construyó una curva de crecimiento en el tiempo para cada aislado y localidad. Posteriormente se realizó una regresión lineal para ajustar las curvas y establecer la asociación entre crecimiento diametral y tiempo, además de determinar las tasas de crecimiento.

La medición del largo y ancho de conidias se realizó en esporas colectadas desde las zonas de crecimiento activo de la colonia (medio AM al $2 \%$ ), las cuales fueron teñidas con una solución acuosa de azul de metileno, y observadas bajo microscopio utilizando el objetivo de 100x. Las imágenes obtenidas se analizaron con el programa computacional de morfometría geométrica TPSdig ${ }^{\circledR}$ ver. 2.16 (Rohlf 2008). En total se midió el ancho y el largo de 50 conidias por cada aislado.

Caracterización molecular. La extracción de ADN se realizó desde colonias del hongo cultivado en AM $2 \%$ por 20 días. El protocolo de extracción correspondió al método descrito por Arismendi et al. (2010). Las secuencias amplificadas correspondieron a la región parcial del gen $18 \mathrm{~S}$ rRNA y el espaciador transcrito interno (ITS). En el cuadro 2 se detallan los partidores de secuencias específicas utilizadas en el estudio (White et al. 1990).

La reacción en cadena de la polimerasa (PCR) se realizó en un volumen de 12,5 $\mu \mathrm{L}$ y consistió en: $1,25 \mu \mathrm{L} 10 \mathrm{X}$ Taq Reaction buffer (200 mM Tris $\mathrm{pH} 8.4,500 \mathrm{mM} \mathrm{KCl}$ ); $25 \mathrm{mM} \mathrm{MgCl}_{2} ; 2,5 \mathrm{mM}$ dNTP's; $10 \mu \mathrm{M}$ de cada partidor (cuadro 2); 0,5 U Taq ADN Polymerasa, Invitrogen; 9,45 $\mu \mathrm{L}$ de $2 \%$ PVP, para $1 \mu \mathrm{L}$ de ADN a una concentración de $60 \mathrm{ng} \mu \mathrm{L}^{-1}$.

El programa del termociclador fue $94{ }^{\circ} \mathrm{C}$ por tres minutos, luego 35 ciclos, donde cada ciclo consistió en 30 segundos a $94^{\circ} \mathrm{C}, 40$ segundos a $57^{\circ} \mathrm{C}$ para los partidores ITS y a $50^{\circ} \mathrm{C}$ para el caso de la región parcial del gen $18 \mathrm{~S}$, luego un minuto a $72{ }^{\circ} \mathrm{C}$, para finalmente 7 minutos a 72 ${ }^{\circ} \mathrm{C}$, por último, mantener a $4{ }^{\circ} \mathrm{C}$.

Cuadro 1. Origen geográfico de los aislados de Neonecria fuckeliana utilizados en el estudio.

Geographical origin of the isolates used in the study.

\begin{tabular}{lcll}
\hline \multicolumn{2}{c}{ Procedencia } & \multicolumn{1}{c}{ Aislados } \\
\cline { 1 - 2 } Localidad & Coordenadas UTM & \\
\cline { 1 - 3 } Carahue & $649600 \mathrm{E}-5723712 \mathrm{~N}$ & & Nf292- Nf293- Nf295- Nf296- Nf298- Nf301- Nf304- Nf306- \\
& $18 \mathrm{H}$ & Nf308- Nf309. \\
Pucón & $250517 \mathrm{E}-5645348 \mathrm{~N}$ & Nf314- Nf315- Nf316- Nf321- Nf322- Nf323- Nf325- Nf327- \\
& $19 \mathrm{H}$ & Nf330- Nf331. \\
Toltén & $661212 \mathrm{E}-5660769 \mathrm{~N}$ & Nf335- Nf336- Nf339- Nf340- Nf344- Nf347-Nf352- Nf356- \\
& $18 \mathrm{H}$ & Nf357- Nf361. \\
Paillaco & $674156 \mathrm{E}-5552199 \mathrm{~N}$ & Nf260- Nf263- Nf266- Nf269- Nf272- Nf275- Nf278- Nf281- \\
\hline
\end{tabular}

Cuadro 2. Nombre y secuencia de partidores universales utilizados (White et al. 1990).

Name and sequence of universal primers used (White et al. 1990).

\begin{tabular}{llccc}
\hline Nombre del partidor & \multicolumn{1}{c}{ Secuencia 5'-3' } & $\begin{array}{c}\text { Temperatura de } \\
\text { alineamiento }\left({ }^{\circ} \mathrm{C}\right)\end{array}$ & $\begin{array}{c}\text { Región } \\
\text { amplificada }\end{array}$ & $\begin{array}{c}\text { Tamaño producto } \\
\text { esperado }(\mathrm{pb})\end{array}$ \\
\hline NS1 & GTA GTC ATA TGC TTG TCT C & 50 & $18 \mathrm{~S}$ & 555 \\
NS2 & GGC TGC TGG CAC CAG ACT TGC & 50 & 57 & 600 \\
\hline ITS5 & GGA AGT AAA AGT CGT AAC AAG G & 57 & 57 \\
ITS4 & TCC TCC GCT TAT TGA TAT GC & 57 & 5 \\
\hline
\end{tabular}


En todos los casos la separación de fragmentos amplificados se evaluó en geles de agarosa al $1 \%$ teñido con bromuro de etidio ( $\left.1 \times 10^{-4} \%\right)$, visualizados en un transluminador de luz UV. La secuenciación de los fragmentos amplificados, se realizó a través del servicio de secuenciación automática de MACROGEN en Corea del Sur.

Análisis de datos. Los datos morfológicos de tasas de crecimiento y tamaño de las conidias se validaron por medio de los supuestos estadísticos de normalidad de residuos con la prueba de Shapiro Wilks y homogeneidad de varianza a través de la prueba de Cochran. Luego se realizó un análisis de varianza paramétrico de un factor para conocer las diferencias intra e inter localidades sobre el largo y ancho de conidias. Además, para identificar los grupos que difieren entre sí, se efectuó una prueba de comparación de medias de Tukey $P \leq 0,05$. Los análisis estadísticos fueron conducidos con el software Statgraphics Centurión (XVI).

Una vez obtenidas las secuencias, se procedió a editarlas con el software Chromas lite y se alinearon con la aplicación web Clustal W. Se realizó un Blast para confirmar la especie e identificar si existen otras secuencias homólogas a los genotipos encontrados. Por otra parte, se realizaron árboles filogenéticos utilizando la metodología de distancias genéticas de neighbor joining con el programa Seaview 4.4.0, esto se realizó con las secuencias obtenidas en el estudio más aquellas descargadas de la base de datos de Genbank.

\section{RESULTADOS}

Distribución geográfica de N. fuckeliana en Chile. El patógeno se encuentra distribuido en las regiones del sur de Chile; desde la costa de Arauco (5860100N - 627358E 18H) en la región del Biobío, hasta Los Muermos (5423863N 636153E 18G) en la región de Los Lagos. La mayor concentración de localidades con presencia de N. fuckeliana se presentó en la zona litoral (figura 1). No se detectaron signos o síntomas del patógeno en plantaciones de las regiones de la zona central de Chile (regiones de Valparaíso al Maule).

Caracterización fenotípica. Los aislados presentaron un micelio aéreo, ralo y en algunos casos viscoso con bordes irregulares. Los colores de colonias obtenidos del crecimiento micelial del hongo, según tabla Munsell fueron, rojo (2,5 YR 4/8), amarillo (2,5Y 7/8) y amarillo pálido (5Y 8/2) (figura $2 \mathrm{~A}, \mathrm{~B}, \mathrm{C}$ ).

Se observó que el color rojo estuvo presente en más del $70 \%$ de las colonias aisladas de cada localidad (figura 2). El color amarillo se presentó en un $10 \%$ de los aislados de Paillaco y Pucón, y el color amarillo pálido en un $10 \%$ de los aislados recuperados de Paillaco, Carahue y Pucón (figura 2).

A los 16 días de incubación, los aislados recuperados desde Pucón y Carahue presentaron los mayores diámetros finales de colonia con promedios de $76,5 \mathrm{~mm}$ y $75,4 \mathrm{~mm}$ respectivamente, mientras que las colonias de Toltén y Pai- llaco obtuvieron diámetros finales promedios de $73,5 \mathrm{~mm}$ y $68,8 \mathrm{~mm}$ respectivamente (figura 3 ). Las tasas de crecimiento diario según el modelo de regresión lineal, arrojó valores de 5,32 para Pucón, 5,23 mm para Carahue, 5,06 mm en el caso de Toltén y por último $4,89 \mathrm{~mm}$ para Paillaco (figura 3).

En relación al tamaño de conidias medidas desde colonias del estado Acremonium-like, el ancho promedio fue de 2,48 $\pm 0,26 \mu \mathrm{m}$ y de 5,09 $\pm 0,56 \mu \mathrm{m}$ de largo. Las conidias de los aislados recuperados de la localidad de Carahue fueron las más anchas con 2,54 $\pm 0,35 \mu \mathrm{m}$, seguido por los aislados de la localidad de Toltén con 2,51 $\pm 0,30 \mu \mathrm{m}$; en tanto que, las conidias más largas con un 5,24 $\pm 0,79 \mu \mathrm{m}$ y $5,14 \pm 0,73 \mu \mathrm{m}$ correspondieron a los aislados de las localidades de Carahue y Pucón. Es importante destacar que en ambos casos (largo y ancho) los aislados de Carahue fueron significativamente superiores $(P<0,05)$ a las demás localidades, al contrario de los aislados de Paillaco que siempre fueron significativamente menores $(P<0,05)$.

$\mathrm{Al}$ calcular el área de la sección transversal de las conidias se observó una relación entre la latitud y el tamaño de conidias, debido a que se produce un gradiente, con conidias de mayor tamaño a medida que las localidades se encuentran más al norte de la distribución, generando el siguiente orden de menor a mayor tamaño de conidias, Paillaco, Pucón, Toltén y por último Carahue (figura 4).

Caracterización molecular. En la amplificación de fragmentos con los partidores ITS, se pudo observar una banda de aproximadamente $600 \mathrm{pb}$ en todos los aislados probados y en el caso del gen $18 \mathrm{~S}$ una banda de $550 \mathrm{pb}$. Cuatro secuencias representativas de cada región de ADN amplificada (ITS y 18S) fueron depositas en Genbank ( $\mathrm{N}^{\circ}$ de acceso a Genbank: KT254323 al KT254330). El análisis Blast confirmó la presencia de una sola especie correspondiente a $N$. fuckeliana. La homología con secuencias de referencia (códigos Genbank KJ022020 y HQ840404) fue alta, con $99 \%$ de identidad para la secuencias ITS y un $100 \%$ para la sección analizada del gen $18 \mathrm{~S}$, En el caso de la amplificación de la región ITS, al revisar las secuencias y realizar el árbol filogenético, se observó que no existieron diferencias, tanto con aislados de Nueva Zelanda recuperados desde $P$. radiata, como tampoco con secuencias de aislados de Europa que fueron recuperados desde coníferas nativas como Picea $s p$. y Larix sp. desde países como Austria, Escocia, Suiza entre otros (figura 5).

En el caso de las secuencias de la región parcial del gen $18 \mathrm{~S}$, solo se encontraron dos secuencias de $N$. fuckeliana en la base de datos de Genbank, los cuales correspondían a aislados recuperados en Europa desde Picea abies (L.) Karst. y de Picea sitchensis (Bong) Carr. (figura 6). La comparación de las secuencias y el árbol filogenético no demostraron diferencias (figura 6), al igual que con la región ITS, generando una politomía para ambas secuencias y por lo tanto no evidenciando diferencias entre aislados de Europa, Nueva Zelanda y Chile. 


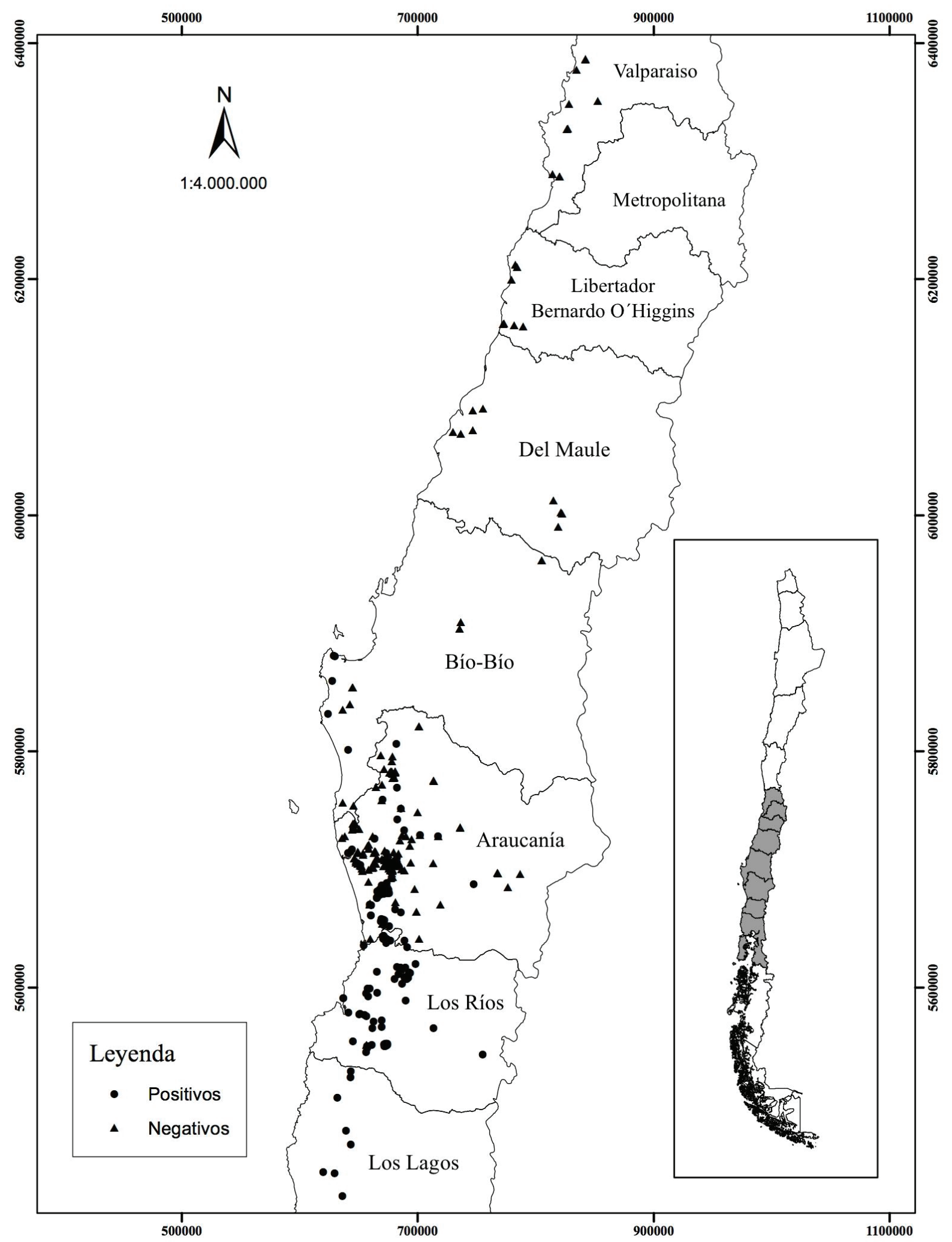

Figura 1. Distribución geográfica de Neonectria fuckeliana determinada en la temporada de 2012-2013 en Chile.

Geographical distribution of Neonectria fuckeliana in Chile (2011-2103 season). 

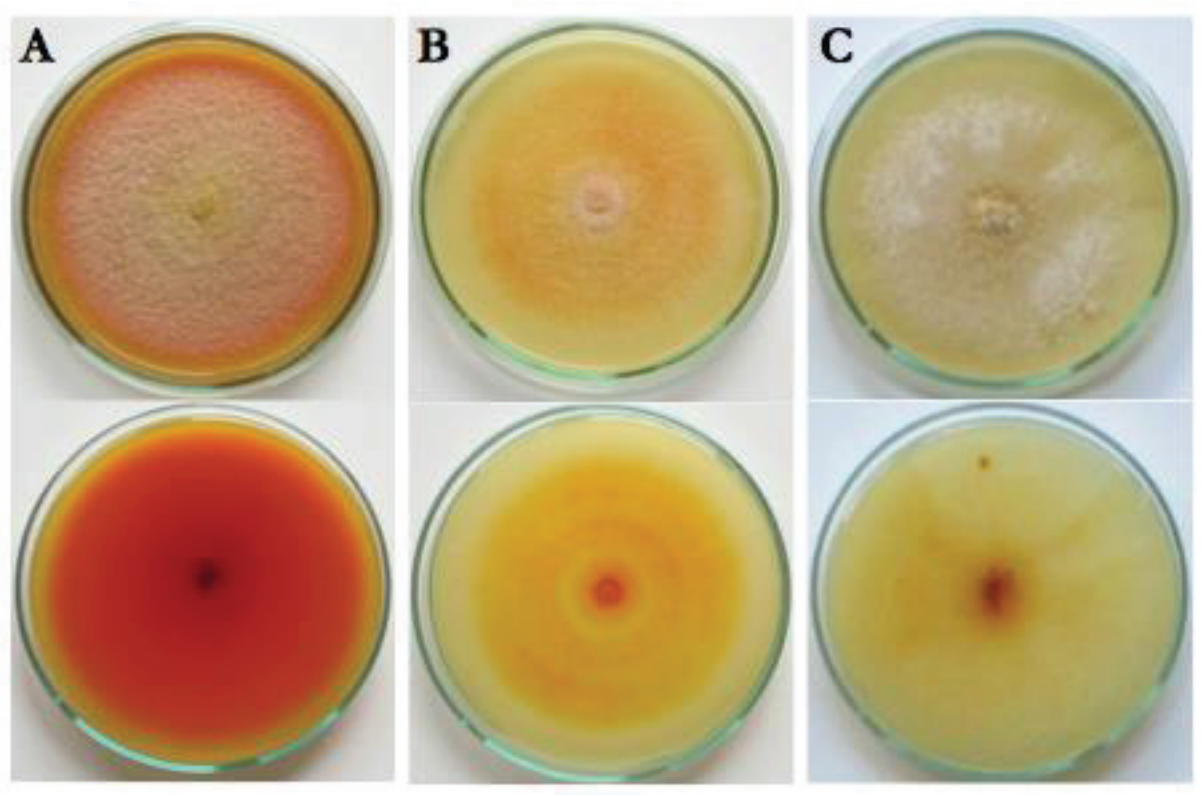

Figura 2. Anverso (arriba) y reverso (abajo) de colonias de Neonectria fuckeliana en Agar Malta al 2\%. A= Aislado Nf314, color rojo (según tabla Munsell 2,5 YR 4/8). B = Aislado Nf327, color amarillo (2,5Y 7/8). C = Aislado Nf266, color amarillo pálido (5Y 8/2).

Characteristic front and back colors of colonies of isolates $N$. fuckeliana studied. A = Isolate Nf314, red (according to table Munsell 2.5 YR 4/8). B = Isolate Nf327, yellow (2.5Y 7/8). C = Isolate Nf266, pale yellow (5Y 8/2).

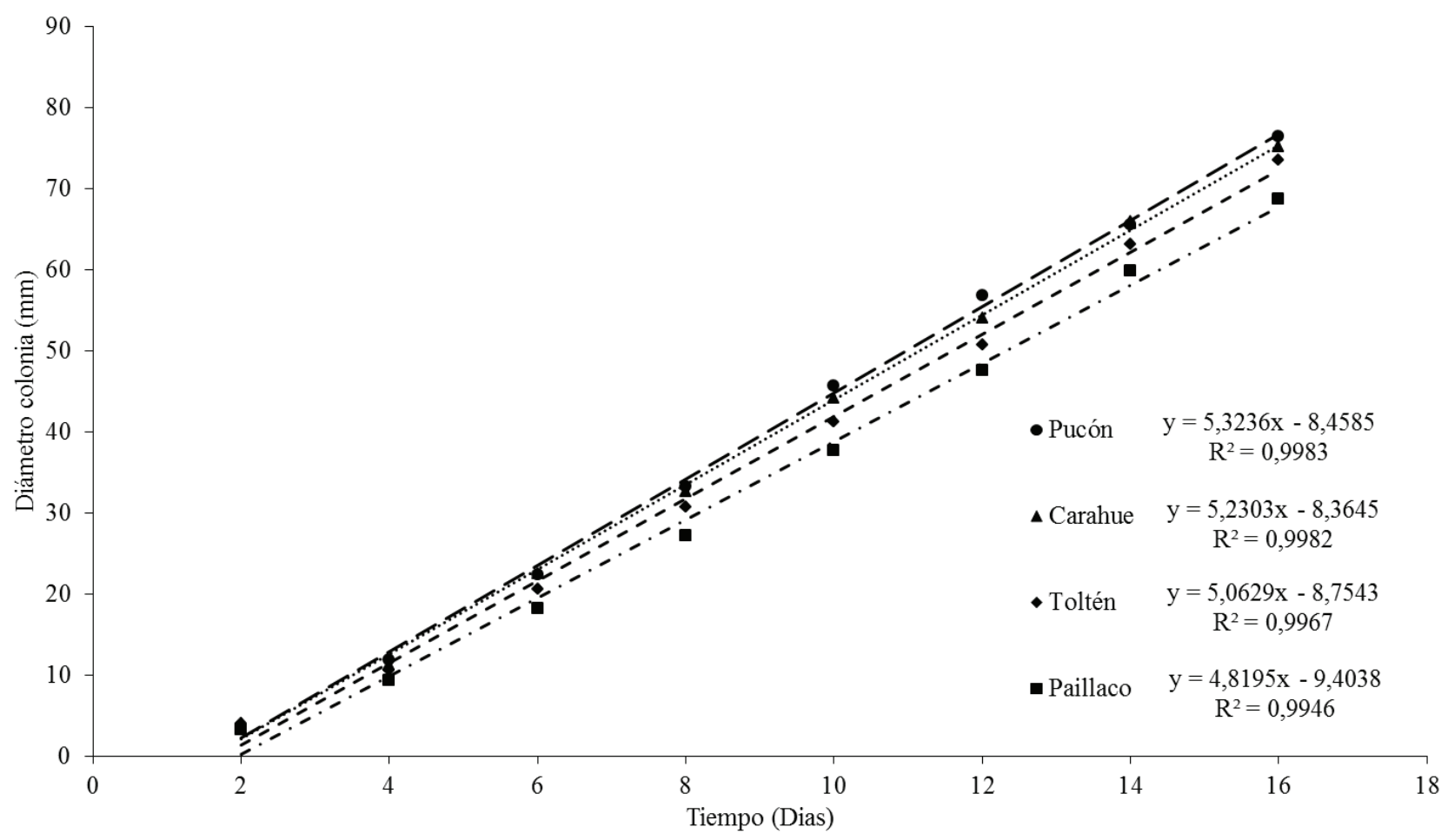

Figura 3. Curvas de regresión lineal con cada ecuación y $\mathrm{R}^{2}(P<0,01)$ del crecimiento acumulado de los aislados de Neonectria fuckeliana para cada localidad, determinado en agar malta al $2 \%$ a $23{ }^{\circ} \mathrm{C}$ en oscuridad.

Cumulative average growth isolated for each locality. 


\section{DISCUSIÓN}

Distribución geográfica. Desde la detección del hongo en Chile el año 2008 en la zona costera de la región de la Araucanía (Morales 2009), se desconocía la distribución de $N$. fuckeliana en Chile. En función de los resultados obtenidos en este trabajo se concluye que, actualmente la enfermedad se presenta en plantaciones de $P$. radiata desde el sur de la Región del Biobío, hasta la Región de Los Lagos, en un amplio transecto de aproximadamente 450 $\mathrm{km}$ a lo largo de la precordillera y Cordillera de la Costa. Hacia el sur se presentó la mayor incidencia y aumentó la presencia de los característicos cancros de los fustes en los rodales visitados. El patógeno no se detectó al norte de este límite geográfico, específicamente al norte de la provincia de Arauco. Esto se puede deber a la menor cantidad de plantaciones de $P$. radiata con manejo de podas y/o a las condiciones climáticas (mayor temperatura y menor humedad, además de menor pluviometría). En el caso de la distribución en Nueva Zelanda, esta se centra en la parte baja de la isla sur de ese país, específicamente en la costa Este entre los paralelos $43^{\circ} \mathrm{S}$ y $46,5^{\circ} \mathrm{S}$. Este lugar se caracteriza por una fuerte influencia oceánica, presencia frecuente de niebla, precipitaciones que van desde los 500

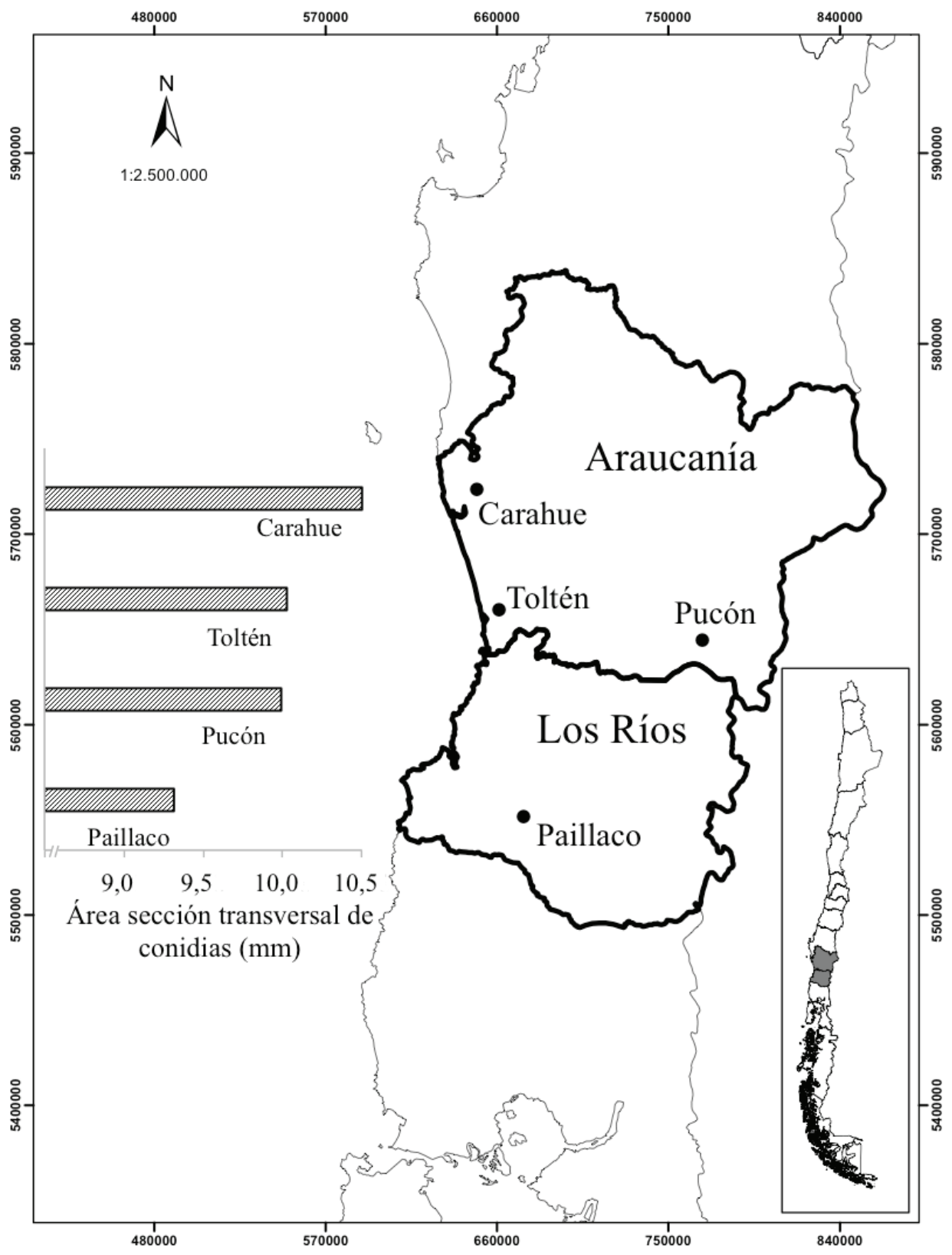

Figura 4. Localidades de muestreo y tamaño (área de la sección transversal) de conidias de Acremonium-like obtenidas in vitro.

Sampling locations and size (cross sectional area) of conidia of Acremonium-like obtained in vitro. 
a los $1.500 \mathrm{~mm}$ anuales y temperaturas medias de $12{ }^{\circ} \mathrm{C}$ (Crane et al. 2009). Condiciones ambientales similares ocurre en Chile en la zona costera de las regiones de La Araucanía y Los Ríos (Dirección Meteorológica de Chile 2008). Esto demuestra la similitud de condiciones climáticas entre los dos países y por tanto el potencial de dispersión de la enfermedad, en zonas con estas características.

Cabe destacar que en Chile la enfermedad no se presenta en sitios de baja productividad, por el contrario, se concentra en plantaciones ubicadas en los sitios de más alta productividad del país (INFOR 1970), aumentando las pérdidas producto de los daños. Según INFOR (2013), de los 1,4 millones de ha de plantaciones de $P$. radiata que posee Chile, aproximadamente el $71 \%$ se encuentra plantado en las regiones donde la enfermedad se encuentra presente. Esto demuestra la potencialidad que tiene este patógeno en tanto siga dispersándose y afectando la especie forestal con mayor valor comercial en Chile.

Caracterización fenotípica. El color predominante de las colonias en todas las localidades fue el rojo. Estudios de Brayford et al. (2004), en Escocia, obtuvieron aislados de

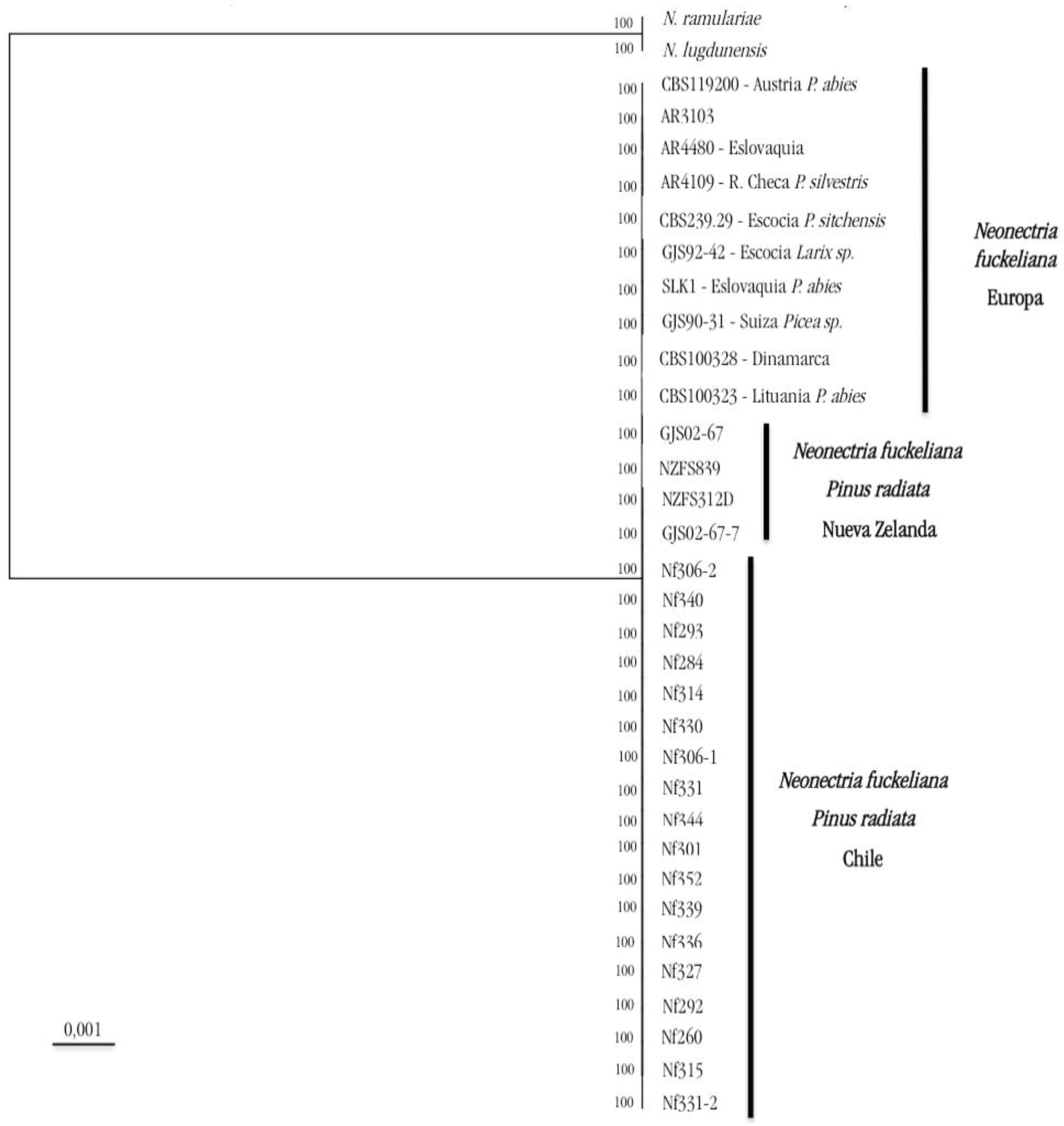

Figura 5. Árbol filogenético utilizando el método de distancias neighbor joining para secuencias ITS de Neonectria fuckeliana obtenidas en este estudio en comparación con secuencias de cepas de Europa y Nueva Zelanda (Grupo externo N. ramularia y N. lugdunensis).

Phylogenetic tree distances using the Neighbor Joining method with ITS sequences of isolates from Europe and New Zealand (external group N. ramularia and $N$. lugdunensis). 
colores amarillo y amarillo pálidos, por lo cual se asemejan en mayor medida a los aislados que en este estudio fueron minoritarias. En el caso de estudios más antiguos realizados por Oullette (1972) con aislados provenientes de Picea glauca (Moench) Voss y Picea abies (L.) Karst en Canadá, las colonias fueron de color rojo y naranjo, siendo mayormente consecuente con los resultados de este estudio. Esto demuestra gran similitud en cuanto a los aislados encontrados en Chile, en lo que respecta al color de la colonia fúngica.

Debido a que los distintos colores de aislados se presentaron en todas las localidades, se descarta que existan tendencias. Esto indica que para esta variable fenotípica, las poblaciones no se encuentran aisladas y por lo tanto carecen de diferencias o estructura poblacional.

Las tasas de crecimiento diario fueron mayores a los valores mencionados en la literatura. Crane et al. (2009), en ensayos con distintas temperaturas de incubación, obtuvieron luego de 16 días, $60 \mathrm{~mm}$ de diámetro, con una tasa de crecimiento diario de 3,75 mm. En el caso de Brayford et al. (2004) en medio de cultivo agar papa sacarosa (PSA) obtuvo una tasa de 1,5 a 3,0 $\mathrm{mm}$ diarios con aislados recuperados desde la corteza de Larix $s p$. de Escocia. Por otro lado Oullette (1972) con aislados obtenidas desde Abies sp., en Quebec, Canadá, obtuvo crecimientos diarios de alrededor de 3,9 $\mathrm{mm}$ en agar malta. Las altas tasas de crecimiento obtenidos en este estudio (entre 4,8 y $5,3 \mathrm{~mm}$ ), se asemejan en mayor medida a los análisis realizados en Canadá y Nueva Zelanda y contrastan con las bajas tasas descritas en los trabajos Europeos. Estos resultados no permiten una comparación directa entre aislamientos de distintos estudios (diversas condiciones de cultivo), pero pueden ser indicadores de la relevancia que significa hacer futuros estudios de virulencia de los aislamientos. En general, en hongos fitopatógenos, las tasas de crecimiento se asocian al grado de virulencia que tienen los distintos aislados (Agrios 2005). La tendencia de obtener mayores tasas de crecimiento en aislados chilenos, fue válida para todas las localidades, que presentaron baja variabilidad entre aislados de un mismo rodal. Por otra parte, se identificó

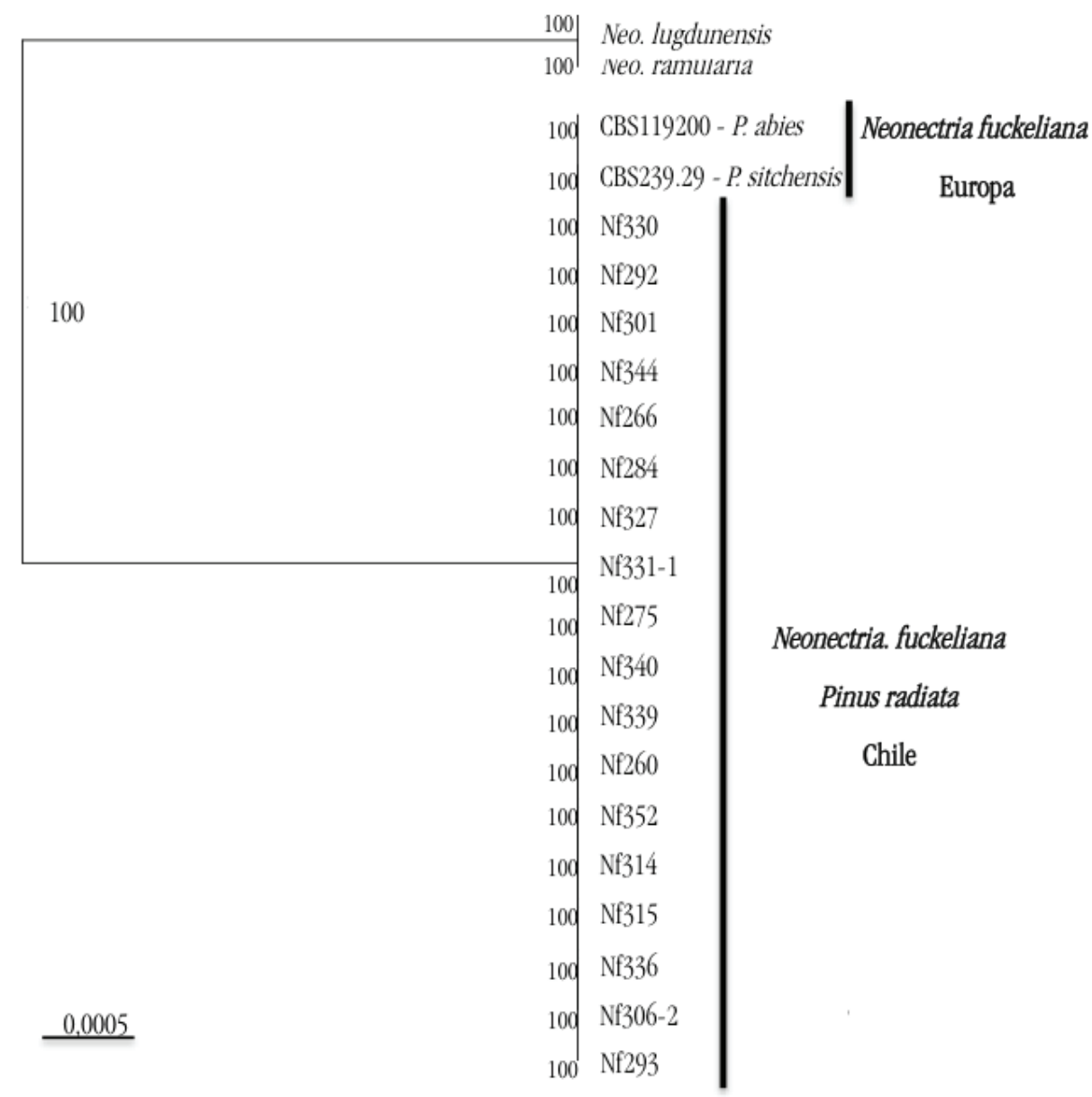

Figura 6. Árbol filogenético utilizando el método de distancias neighbor joining para la secuencia parcial del gen $18 \mathrm{~S}$ del estudio con secuencias de aislados de Europa (Grupo externo Neonectria ramularia y Neonectria lugdunensis).

Phylogenetic tree distances using the Neighbor Joining method for the partial sequence of the $18 \mathrm{~S}$ gene with European isolates (external group N. lugdunensis and N. ramularia). 
un gradiente latitudinal, con menores tasas de crecimiento desde el norte hacia el sur de su área de distribución.

Los tamaños de las conidias (largo y ancho), concuerdan con resultados de distintos autores (Oullette 1972, Brayford et al. 2004), donde todos obtuvieron valores que fluctuaron entre 3 y $8 \mu \mathrm{m}$ de largo y entre 1,5 y $4 \mu \mathrm{m}$ de ancho. Al analizar los tamaños de conidias obtenidos en Chile, se observa una tendencia a disminuir desde los aislados recuperados en poblaciones de más al norte hacia aquellos obtenidos de plantaciones de más al sur. Este gradiente norte/sur es similar al observado en las tasas de crecimiento del micelio (mayores en la zona norte y menores en la zona sur). Estas diferencias a nivel morfológico pueden estar originando lo que se denominan morfotipos. Los cuales son grupos de individuos de una misma especie que presentan diferencias a nivel morfológico (Hawksworth et al. 1985). Un ejemplo de esto se da con el hongo Diplodia pinea (Desm.) Kick (=Sphareopsis sapinea (Fr.) Dyko and Sutton), donde se pueden presentar hasta tres morfotipos, que difieren entre sí de acuerdo a las tasas de crecimiento, forma y color de colonias, tamaño y forma de las conidias y por último al hospedante de donde se obtengan los aislados (De Wet et al. 2000, Burgess et al. 2001).

Caracterización molecular. La secuenciación de las regiones ITS y de la región parcial del gen 18S, ratificaron que la especie presente en Chile corresponde a $N$. fuckeliana, debido a la comparación con secuencias homólogas de la base de datos del Genbank, esto confirma la identificación por claves taxonómicas realizada por Morales (2009). Además, se establece la presencia de una sola especie por la ausencia de diferencias genéticas en las secuencias estudiadas que son relativamente conservadas intraespecíficamente.

Al comparar las secuencias de ADN obtenidas en este estudio, con secuencias de N. fuckeliana descrita en Europa y Nueva Zelanda, no existen mayores diferencias para la región del genoma analizado. Esto indicaría una baja diversidad genética global de la especie ya que los aislados de Europa incluso se obtuvieron de coníferas nativas distintas a $P$. radiata (Chaverri et al. 2011). Por el contrario, cuando existen diferencias de linajes muy acentuadas (alta diversidad), incluso regiones relativamente conservadas del ADN como ITS, muestran diferencias intraespecífica (White et al. 1990). En ocasiones el componente genético que otorga diferencias fenotípicas está determinado por uno o por muy pocos genes y por lo tanto es necesario utilizar un gran número de marcadores para detectar posibles polimorfismos puntuales. Esto explicaría porque se detectan diferencias morfológicas en los aislamientos que no se ven reflejados a nivel del análisis genético.

Adicionalmente, una baja diversidad genética se puede atribuir a lo reciente de la introducción del hongo a Chile y el consiguiente efecto de "cuello de botella" que usualmente restringe el reservorio genético. Es probable que el inóculo haya provenido de un mismo origen geográfico, limitando aún más la diversidad genética de este hongo en Chile. La baja diversidad que puede presentarse dentro de una misma población ha sido documentada en Europa. Utilizando un partidor M13 y solo con análisis de patrón de bandas de productos PCR, se determinó un alto grado de polimorfismo entre aislados de localidades de Suecia y Lituania. Sin embargo, no encontraron diferencias intrapoblacionales. Esta alta diferenciación entre localidades se atribuye al efecto que posee el mar Báltico como una barrera geográfica que genera un aislamiento reproductivo (Vasiliauskas y Jan Stenlid 1997). Dentro de Chile no se esperaría una diferenciación genética tan marcada entre poblaciones ya que dentro de su distribución actual no existen grandes barreras geográficas que limiten el flujo génico.

Por otra parte, la reciente identificación del patógeno en el país (Morales 2009), hace suponer que la presencia de este agente es relativamente nueva en Chile. Por ello, y a pesar de que el hongo presenta una reproducción sexual abundante (fácil de observar en terreno), la especie no habría tenido tiempo suficiente para pasar por sucesos (mutaciones, recombinación y/o selección) que generen una diversidad o diferenciación genética marcada.

\section{CONCLUSIONES}

Se confirma por análisis moleculares, a través de secuencias ITS y de la región parcial del gen 18S, que la especie presente en Chile corresponde a $N$. fuckeliena. Esta se encuentra en las regiones de mayor importancia forestal de Chile (Biobío, La Araucanía, Los Ríos y Los Lagos).

Existen al menos tres colores de colonias de $N$. fuckeliana que predominan dentro de los aislados del estudio (rojo- amarillo y amarillo pálido). Los aislados de la región de La Araucanía presentan tasas de crecimiento y tamaños de conidias mayores a los de los aislados de la región de Los Ríos, lo que demostraría la existencia de diferencias fenotípicas entre aislados de N. fuckeliana en Chile.

La caracterización molecular de $N$. fuckeliana a través de las secuencias ITS y la región parcial del gen 18S, demuestra que no existen diferencias genéticas entre aislados chilenos. Comparaciones con secuencias de aislados de Europa y Nueva Zelanda, muestran altas homologías con aquellas de los aislados de $N$. fuckeliana de Chile.

\section{AGRADECIMIENTOS}

Los autores agradecen al proyecto Fondo SAG "Ciclo biológico y aspectos epidemiológicos de Neonectria fuckeliana o revirado del pino en plantaciones de Pinus radiata. Estrategias para el control de la enfermedad", por el financiamiento de este estudio. Además a las profesionales de SAG- Araucanía, Maritza Schafer, y de CONAF-Araucanía, Mónica González, por los antecedentes proporcionados en la prospección de la enfermedad en terreno. 


\section{REFERENCIAS}

Agrios GN. 2005. Plant Pathology. San Diego, CA, USA. Academic Press. 922 p.

Arismendi N, N Andrade, R Riegel, R Carrillo. 2010. Presence of a phytoplasma associated with witches' broom disease in Ugni molinae Turcz. And Gaultheria phillyreifolia (Pers.) sleumer determined by DAPI, PCR, and DNA sequencing. Chilean Journal of Agricultural Research 70(1): 26-33.

Brayford D, B Honda, F Martini, G Samuels. 2004. Neonectria and Cylindrocarpon: the Nectria mammoidea group and species lacking microconidia. Mycologia 96(3): 572-597.

Burgess T, BD Wingfield, MJ Wingfield. 2001. Comparison of genotypic diversity in native and introduced populations of Sphaeropsis sapinea isolated from Pinus radiate. Mycological Research 105: 1331-1339.

Castlebury LA, AY Rossman, AS Hyten. 2006. Phylogenetic relationships of Neonectria/Cylindrocarpon on Fagus in North America. Canadian Journal of Botany 84: 1417-1433.

Chaverri P, C Salgado, Y Hirooka, AY Rossman, GJ Samuels. 2011. Delimitation of Neonectria and Cylindrocarpon (Nectriaceae, Hypocreales, Ascomycota) and related genera with Cylindrocarpon-like anamorphs. Studies in Myco$\log y$ 68: 57-78.

Crane PE, AJ Hopkins, MA Dick, LS Bulman. 2009. Behaviour of Neonectria fuckeliana causing a pine canker disease in New Zealand. Canadian Journal of Forest Research 39: 2119-2128.

De Wet J, MJ Wingfield, TA Coutinho, WD Wingfield. 2000. Characterization of Sphaeropsis sapinea isolates from South Africa, Mexico and Indonesia. Plant Disease 84: 151-156.

Dick M, P Crane. 2009. Neonectria fuckeliana is pathogenic to Pinus radiate in New Zealand. Australasian Plant Disease Notes 4: 12-14.

Dirección Meteorológica de Chile. 2008. Guía Climática Práctica. Consultado 01 abr. 2015. Disponible en http://www. meteochile.gob.cl/climatologia.php/

Hawksworth D, B Sutton, G Ainsworth. 1985. Ainsworth's and Bisby's Dictionary of the Fungi. 7th ed. Wallingford, UK. CAB International. $412 \mathrm{p}$.

Hopkins A, M Dick, C Carlson, P Crane. 2012. Early investigations into the infection courts used by Neonectria fuckelia- na to enter Pinus radiata stems. European Journal of Plant Pathology 132: 537-548.

INFOR (Instituto Forestal, CL). 1970. Índices de sitio para pino insigne en Chile. Santiago, Chile. INFOR. 27p.

INFOR (Instituto Forestal, CL). 2013. Anuario forestal 2013. Boletín estadístico No 140 . Santiago, Chile. INFOR.

Molina E, R Morales, E Valenzuela, I Vives. 2012. Caracterización morfológica de Acremonium sp. asociado a Neonectria fuckeliana en Pinus radiata. Boletín Micológico 27 (2): 32-38.

Morales RA. 2009. Detección de Neonectria fuckeliana en Chile, asociado a cancros y malformaciones fustales en plantaciones de Pinus radiata. Bosque 30(2): 106-110.

Morales R, E Molina, M Osorio, I Vives, C González, JC Carmona. 2013. Detección del sinanamorfo Cylindrocarpon cylindroides var. tenue sobre cancros causados por Neonectria fuckeliana en Pinus radiata. Boletín Micológico 28 (2): 53-57.

Munsell Color Company. 1971. Munsell soil color charts. Baltimore. USA.

Osorio M, C González, R Morales, I Vives, E Molina, JC Carmona. 2014. Relación in vitro entre Cylindrocarpon cylindroides y Neonectria fuckeliana asociados a cancros fustales de Pinus radiata en Chile. Boletín Micológico 29 (1): 18-27.

Ramsfield TD, MWP Power, MO Kimberley. 2013. The relationship between pruning and the incidence of Neonectria fuckeliana in Pinus radiata. New Zealand Journal of Forestry Science 2013: 43: 13.

Rohlf J. 2008. tpsDig Version 2.16. Ecology \& Evolution. Stony Brook, New York, USA. State University of New York.

Roll-Hansen F, H Roll-Hansen. 1979. Microflora of sound-looking wood in Picea abies stems. European Journal of Forest Pathology 9: 308-316.

Vasiliauskas R, J Stenlid. 1998. Fungi inhabiting stems of Picea abies in a managed stand in Lithuania. Forest Ecology and Management 109: 119-126.

Vasiliauskas R, J Stenlid. 1997. Population structure and genetic variation in Nectria fuckeliana. Canadian Journal of Botany 75 : 1707-1713.

White TJ, T Bruns, S Lee, J Taylor. 1990. Amplification and direct sequencing of fungal ribosomal RNA genes for phylogenetics. In MA Innis, DH, Gelfand JJ Sninsky, TJ White eds. PCR protocols: a guide to methods and applications. San Diego, USA. Academic Press. p. 315-322. 
